Article

\title{
Properties Enhancement of High Molecular Weight Polylactide Using Stereocomplex Polylactide as a Nucleating Agent
}

\author{
Purba Purnama ${ }^{1, *}$, Muhammad Samsuri ${ }^{2}$ and Ihsan Iswaldi ${ }^{1}$ D \\ 1 School of Applied STEM, Universitas Prasetiya Mulya, Tangerang, Banten 15339, Indonesia; \\ ihsan.iswaldi@prasetiyamulya.ac.id \\ 2 Chemical Engineering Department, Universitas Bhayangkara Jakarta Raya, Bekasi 17121, Indonesia; \\ msamsuri79@gmail.com \\ * Correspondence: purbapur@gmail.com
}

check for updates

Citation: Purnama, P.; Samsuri, M.; Iswaldi, I. Properties Enhancement of High Molecular Weight Polylactide Using Stereocomplex Polylactide as a Nucleating Agent. Polymers 2021, 13, 1725. https://doi.org/10.3390/ polym 13111725

Academic Editor: Shinichi Sakurai

Received: 23 April 2021

Accepted: 12 May 2021

Published: 25 May 2021

Publisher's Note: MDPI stays neutral with regard to jurisdictional claims in published maps and institutional affiliations.

Copyright: (c) 2021 by the authors. Licensee MDPI, Basel, Switzerland. This article is an open access article distributed under the terms and conditions of the Creative Commons Attribution (CC BY) license (https:// creativecommons.org/licenses/by/ $4.0 /)$.

\begin{abstract}
As one of the most attractive biopolymers nowadays in terms of their sustainability, degradability, and material tune-ability, the improvement of polylactide (PLA) homopolymer properties by studying the utilization of stereocomplex polylactide (s-PLA) effectively and efficiently is needed. In this sense, we have studied the utilization of s-PLA compared to poly D-lactide (PDLA) homopolymers as a nucleating agent for PLA homopolymers. The mechanical and thermal properties and crystallization behavior of PLA homopolymers in the presence of nucleating agents have been evaluated using a universal testing machine, differential scanning calorimeter, and X-ray diffractometer instruments, respectively. PDLA and s-PLA materials can be used to increase the thermal and mechanical properties of poly L-lactide (PLLA) homopolymers. The s-PLA materials increased the mechanical properties by increasing crystallinity of the PLLA homopolymers. PLLA/s-PLA enhanced mechanical properties to a certain level (5\% s-PLA content), then decreased them due to higher s-PLA materials affecting the brittleness of the blends. PDLA homopolymers increased mechanical properties by forming stereocomplex PLA with PLLA homopolymers. Non-isothermal and isothermal evaluation showed that s-PLA materials were more effective at enhancing PLLA homopolymer properties through nucleating agent mechanism.
\end{abstract}

Keywords: polylactide; stereocomplex; nucleating agent; biopolymer; polymer blend

\section{Introduction}

The development of future materials is focused on their sustainability, degradability, and material tune-ability. Sustainability is an important parameter to ensure material resources will have a long life. Material tune-ability is a specific characteristic, which refers to the ability to alter and adjust the properties of the material to suit existing applications. Degradability is related to the environmental issues caused by material waste. Environmental problems receive more attention to recycle or develop the non-degradable material. Accumulation of non-degradable waste from the high consumption of fossil fuels-based materials in various applications causes tremendous environmental problems. Recently, many researchers have focused on the development and modification of the physical-mechanical properties of biodegradable polymers to substitute these for traditional polymers.

Polylactide (PLA) is one of the most attractive biopolymers with many advantages that comply with future material development, such as sustainability, biodegradability, biocompatibility, and properties modification. PLA is a bio-based polymer that is commercially available and has accomplished large-scale production since 2001 [1,2]. It has the potential to replace fossil-based polymers due to its biodegradability and biocompatibility $[3,4]$. PLA is a stiff and brittle material at room temperature with a glass transition temperature of $\sim 55^{\circ} \mathrm{C}$ and a melting temperature of $180^{\circ} \mathrm{C}$. It has weaknesses such as a low crystallization rate and heat distortion temperature, as well as insufficient crystallization ability during common industrial processes. As a thermoplastic biopolymer, it can be amorphous or 
semicrystalline in nature depending on its enantiomeric structures: Poly L-lactide (PLLA), Poly D-lactide (PDLA), or Poly DL-lactide (PDLLA).

Commercial PLA made from L-lactide is a brittle material. The limitation in its thermal and mechanical stability restricts its wide application to replace oil-based polymers that require high impact strength [5]. Industrial processing of PLA results in a low heat distortion temperature due to its low crystallization rate and degree of crystallinity in a short processing time [6,7]. Considering its wide potential market, enhancement of the properties of PLA is mandatory in order to comply with specific applications. Blending PLA with other materials has been explored for the specific enhancement of PLA properties. The addition of plasticizers into the PLA matrix can reduce its brittleness and enhance its life span. Mixing PLLA and PDLA enantiomers forma stereocomplex PLA (s-PLA) with a different crystal structure and higher thermal and mechanical properties [8-10]. Furthermore, the blending of PLA with nucleating agents could improve its thermal and mechanical properties as well as increasing its crystallinity.

As the crystal structure of s-PLA has unique characteristics with higher thermal and mechanical properties, crystalline s-PLA can be utilized as a nucleating agent to improve the thermal and mechanical properties of PLA $[8,11]$. Many studies have reported strategies to improve the properties of PLA through s-PLA formation [12-17].

Rahman et al. reported that the addition of PDLA into PLLA accelerated the crystallization of PLLA homopolymer through enhancement of the nucleation process, but slightly interfered with the crystallization growth [12]. The equimolar addition of high molecular weight PDLA ( $\mathrm{Mw}>2 \times 10^{5} \mathrm{~g} / \mathrm{mol}$ ) into PLLA homopolymer above melting temperature preferably crystallizes to form s-PLA [13]. Ji et al. reported the increasing crystallization rate and nucleation site of PLLA and PDLA homopolymer in the presence of low molecular weight s-PLA [14]. The presence of poly DL-lactide copolymer in the PLLA and PDLA mixture inhibited PDLA chain diffusion during the crystallization process of s-PLA formation [15]. The presence of s-PLA crystalline with various chain structures in the PLA brings higher mechanical and thermal properties [16]. Property enhancement by s-PLA will affect PLA processing: thermal processing, additive manufacturing, and solution casting [17]. Thermal and mechanical enhancement of PLA through stereocomplexation has been utilized to obtain stable PLA materials which are suitable for many applications, especially use as high-performance materials [8,14-21]. The mechanical and thermal properties of s-PLA are higher than those of pure PLA films, which is caused by the strong molecular interactions (hydrogen bonds and dipole-dipole interactions) of PLLA and PDLA chains [21-24].

The stereocomplexation of PLA is a very well-known strategy for enhancing the properties of PLA-based materials by blending PLLA and PDLA homopolymers. But, it is requires an effective s-PLA production method. Previously, we have developed the effective stereocomplexation of high-molecular-weight PLA through supercritical fluid technology [24-26]. s-PLA also has some constraints for its use in real applications due to its melt stability during thermal processing in industries and also the high cost of PDLA in equimolar ratio with PLLA. Nevertheless, with its crystalline structure and characteristics, s-PLA materials can be used as a nucleating agent. Additionally, the material form of s-PLA is important to comply with industrial processing. By using supercritical fluid technology, a perfect s-PLA is obtained in a dry, powder form which is suitable to be used as a nucleating agent [24]. Utilization of s-PLA materials as a nucleating agent (additives) instead of PDLA homopolymer will reduce the use of PDLA by up to a half. As commercial applications require competitive costs, the low consumption of PDLA homopolymer will be beneficial for reducing production costs.

For these reasons, it is necessary to find an effective and efficient utilization of s-PLA to improve PLA homopolymer properties. In this work, we have studied the utilization of s-PLA compared to PDLA homopolymers as a nucleating agent for PLA homopolymers. We have evaluated the mechanical, thermal properties, and crystallization behavior of PLA homopolymers in the presence of nucleating agents. 


\section{Materials and Methods}

\subsection{Materials}

L-Lactide (L-LA) and D-Lactide (D-LA) were purchased from Corbion (Amsterdam, The Netherlands). Tin(II)bis(2-ethylhexanoate) $\left(\mathrm{Sn}(\mathrm{Oct})_{2}\right)$ (Sigma Chemical Co., St. Louis, MO, USA, purity $\geq 99 \%$ ) and 1-dodecanol (DoOH) (Sigma-Aldrich, St. Louis, MO, USA, purity $\geq 99.5 \%$ ) were purified by distillation under reduced pressure and dissolved in dry toluene. The toluene was dried by refluxing over a benzophenone-Na complex and distilled in a nitrogen atmosphere just prior to use. High molecular weight PLLA $\left(M_{n}=181,493 \mathrm{~g} / \mathrm{mol}, M_{w}=425,561 \mathrm{~g} / \mathrm{mol}, \mathrm{PDI}=2.345\right)$ was synthesized by ring-opening polymerization of L-lactide (Corbion, Amsterdam, The Netherlands) at $130^{\circ} \mathrm{C}$ for $24 \mathrm{~h}$. Other PLA homopolymers for nucleating agent materials: PDLA $\left(M_{n}=\sim 87,000 \mathrm{~g} / \mathrm{mol}\right.$, $\left.M_{w}=\sim 125,000 \mathrm{~g} / \mathrm{mol}, \mathrm{PDI}=1.437\right)$ and PLLA $\left(M_{n}=\sim 87,000 \mathrm{~g} / \mathrm{mol}, M_{w}=153,000 \mathrm{~g} / \mathrm{mol}\right.$, PDI $=1.759)$ were also synthesized by a similar method. Dichloromethane (JT Baker, HPLC grade) and $\mathrm{CO}_{2}$ (Purity $\geq 99.9 \%$ ) were used as received.

\subsection{Stereocomplex Formation}

The s-PLA was synthesized by combining PDLA $\left(M_{n}=\sim 87,000 \mathrm{~g} / \mathrm{mol}, M_{w}=\right.$ $\sim 125,000 \mathrm{~g} / \mathrm{mol}$, PDI $=1.437)$ and PLLA $\left(M_{n}=\sim 87,000 \mathrm{~g} / \mathrm{mol}, M_{w}=153,000 \mathrm{~g} / \mathrm{mol}\right.$, PDI $=1.759)$ with $1: 1$ weight ratio and processed through supercritical carbon dioxidedichloromethane [24]. The processing condition was optimized at $65{ }^{\circ} \mathrm{C}$ to achieve a pressure of 350 bar and allowed to proceed for the predetermined times $(5 \mathrm{~h})$. The reactor was opened immediately after the reaction had finished obtaining a dry and powdershaped s-PLA.

\subsection{Polylactide Blending}

S-PLA and D-lactide were prepared as nucleating agents for high molecular weight PLLA materials. PLA blends were prepared by adding s-PLA particles or PDLA homopolymer with various contents into PLLA materials by a solution casting method. We denoted these as PLLA/PDLAx and PLLA/s-PLAx for the blends containing PDLA and s-PLA, respectively. The $x$ values represent the PDLA or s-PLA content in the blends. PLLA/s-PLA3, PLLA/s-PLA5, and PLLA/s-PLA10 represent the PLA blends with $3 \%, 5 \%$, and $10 \%$ of s-PLA particle content, respectively. In a similar notation, PLLA/PDLA3, PLLA/PDLA5, and PLLA/PDLA10 represent the PLA blends with 3\%, 5\%, and 10\% of PDLA content, respectively. Neat PLLA homopolymers were used as control materials. The mixture was dissolved in dichloromethane with total polymer to total solvent ratio (weight to volume) of approximately 5:100. The mixture was vigorously stirred for $4 \mathrm{~h}$ and poured into a petri glass. It then underwent evaporation at room temperature for $24 \mathrm{~h}$ and was subsequently placed in a vacuum condition at $80^{\circ} \mathrm{C}$ for $48 \mathrm{~h}$.

\subsection{Characterization}

The PLA blend films were characterized to evaluate the enhancement of their mechanical and thermal properties. The mechanical testing method is adopted from ASTM D-638 to evaluate tensile properties. The mechanical properties of the PLA blends were measured by Universal Testing Machine (6800 Series, Instron, Norwood, MA, USA) apparatus with a specimen size of $20 \mathrm{~mm} \times 5 \mathrm{~mm}$ and sample thickness of approximately $80 \mu \mathrm{m}$. The distance between the supports was $10 \mathrm{~mm}$ and the extension rate was $1 \mathrm{~mm} / \mathrm{min}$. The thermal properties of PLA blends were evaluated using a modulated differential scanning calorimeter (Modulated DSC 2910, TA Instrument, New Castle, DE, USA). The heating rate was fixed at $10^{\circ} \mathrm{C} / \mathrm{min}$. Isothermal and non-isothermal crystallizations were evaluated by varying cooling rates and crystallization temperature, respectively. $\mathrm{X}$-ray diffraction spectra were registered with an X-ray diffractometer D/Max-2500 (Rigaku, Japan) composed of

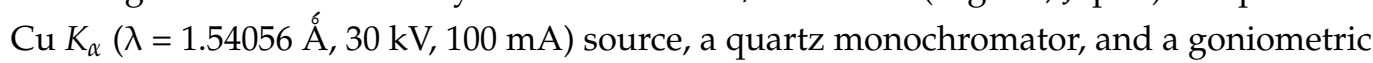
plate. A polarized optical microscope was also used to evaluate crystal growth during the isothermal and non-isothermal crystallization processes. 


\section{Results and Discussions}

The s-PLA and PDLA we investigated are nucleating agents for PLLA homopolymers. Various reports have studied the nucleating effect of s-PLA by combining PDLA into PLLA homopolymer. Here, we report the use of real s-PLA materials to evaluate the nucleating effect of PLLA homopolymers compared to PDLA as a nucleating agent.

The use of s-PLA as a nucleating agent was successfully synthesized through supercritical carbon dioxide-dichloromethane [24]. The s-PLA and PDLA were evaluated by DSC and XRD instruments to confirm the characteristics of the materials as shown in Figure 1. The synthesized s-PLA crystalline shows a single peak at $\sim 12^{\circ}$ of $2 \theta$ compared with PLLA and PDLA at $\sim 17^{\circ}$ and $19^{\circ}$ of $2 \theta$ which indicates the change of crystal structure and helical conformation of PLLA and PDLA driven by hydrogen bonding interactions. The different diffraction peaks mean that all of the PLLA and PDLA blends successfully formed s-PLA [20]. The s-PLA formation was also confirmed by its single melting temperature $\left(T_{m}\right)$ at $230^{\circ} \mathrm{C}$, which was $50^{\circ} \mathrm{C}$ higher than $T_{m}$ of homopolymers $\left(\sim 180^{\circ} \mathrm{C}\right)$.

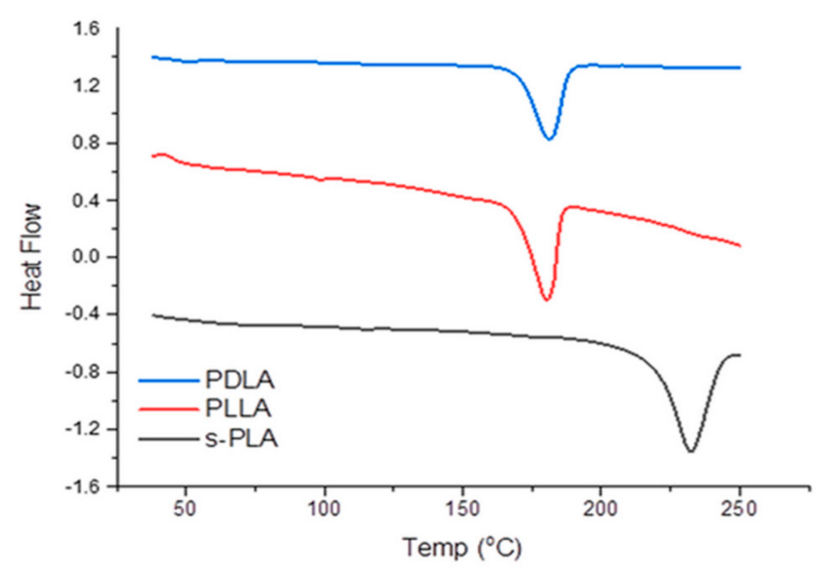

(a)

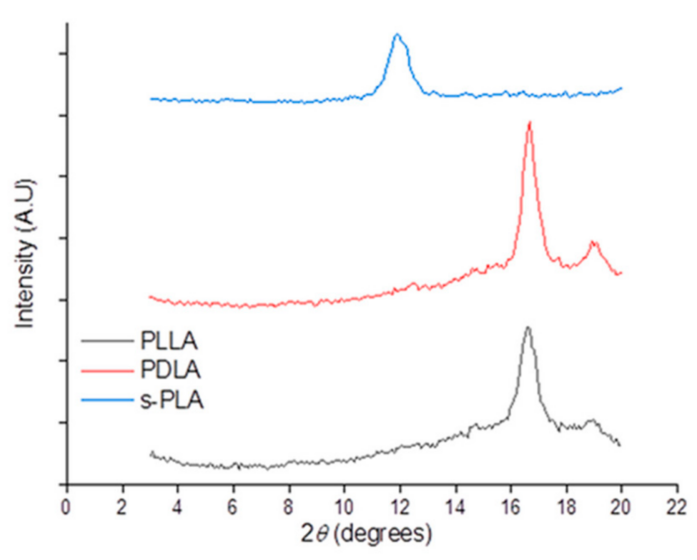

(b)

Figure 1. Materials (PLLA, PDLA, and s-PLA) characteristic comparison: (a). DSC thermogram; (b). X-ray diffraction patterns.

The s-PLA can be produced by solvent casting [11-15,21,27], thermal processing [28,29], microwave irradiation [30], and the supercritical fluid technology method [24-26]. The solvent casting and thermal processing methods have molecular weight constraints to generate perfect s-PLA materials [21,28]. The microwave irradiation method is a fast and efficient process to produce bulk s-PLA materials in a short time [30]. However, it has limitations in producing s-PLA on a large scale. In this work, we obtained s-PLA using supercritical carbon dioxide-dichloromethane. The supercritical carbon dioxidedichloromethane generated perfect dry and powder-shaped s-PLA materials [24]. It is also possible to scale up this process into commercial production. Furthermore, a dry and powder-shaped s-PLA material is suitable for use as additives in industrial application.

The addition of nucleating agent into the polymer matrix was adopted to improve or enhance specific matrix properties. Improvement of the properties of PLA homopolymers is important in replacing conventional polymeric materials. The addition of s-PLA or PDLA as the nucleating agent was expected to improve the mechanical properties of PLLA homopolymer. The nucleating agent's amounts in the PLLA homopolymer were varied at $3 \%, 5 \%$, and $10 \%$ weight ratios. The PLLA mechanical properties enhancement with the addition of s-PLA and PDLA are tabulated in Table 1. 
Table 1. The mechanical properties of PLLA homopolymers with addition of s-PLA and PDLA as the nucleating agent.

\begin{tabular}{cccc}
\hline Materials & $\begin{array}{c}\text { Elongation at Break } \\
(\mathbf{\%})\end{array}$ & $\begin{array}{c}\text { Tensile Strength } \\
\mathbf{( M P a )}\end{array}$ & $\begin{array}{c}\text { Young's Modulus } \\
(\mathbf{G P a})\end{array}$ \\
\hline Neat PLLA & $5.10 \pm 0.26$ & $86.26 \pm 4.31$ & $2.27 \pm 0.10$ \\
PLLA/s-PLA3 & $4.97 \pm 0.20$ & $108.22 \pm 5.19$ & $2.95 \pm 0.12$ \\
PLLA/s-PLA5 & $4.65 \pm 0.17$ & $115.22 \pm 5.42$ & $3.22 \pm 0.14$ \\
PLLA/s-PLA10 & $3.83 \pm 0.11$ & $98.33 \pm 3.44$ & $3.28 \pm 0.15$ \\
PLLA/PDLA3 & $5.22 \pm 0.26$ & $94.86 \pm 2.94$ & $2.47 \pm 0.10$ \\
PLLA/PDLA5 & $5.29 \pm 0.24$ & $94.21 \pm 2.73$ & $2.61 \pm 0.09$ \\
PLLA/PDLA10 & $5.43 \pm 0.22$ & $95.93 \pm 4.03$ & $2.67 \pm 0.10$ \\
\hline
\end{tabular}

The addition of s-PLA or PDLA improves the mechanical properties of PLLA homopolymer. The Young's modulus of PLLA homopolymer with s-PLA content of 3\%, 5\%, and $10 \%$ increased by $29.90 \%, 41.74 \%$, and $44.47 \%$, respectively. The s-PLA additions also increased tensile strength up to the addition of 5\% s-PLA, then decreased at the addition of $10 \%$ of s-PLA. The s-PLA slightly reduced PLLA homopolymer elongation at $3 \%$ and $5 \%$, but this drastically reduced at $10 \%$ of s-PLA contents. On the other hand, the addition of PDLA only increased Young's modulus of PLLA by $17.66 \%$ at the same content. It also slightly increased tensile strength by $11.21 \%$ but increased elongation at break.

Previous studies generally focus on the enhancement of PLA properties through the formation of s-PLA materials from PLLA and PDLA with various blending ratios [9-15,27]. The mechanical properties of s-PLA increase with an equivalent ratio of PLLA and PDLA, such as Young's modulus by up to $25 \%$ [24]. The enhancement of mechanical properties also depends on the ratio of PLLA to PDLA [14,28]. In general, the mechanical properties of PLA blends improve by up to $25 \%$ (Young's modulus) with $50 \%$ of PDLA, then decrease when increasing the PDLA portion [31]. In this work, the addition of s-PLA and PDLA as nucleating agents increased the tensile strength and Young's modulus of PLA material. Overall, s-PLA and PDLA nucleating agents improve mechanical properties. Moreover, s-PLA makes significant improvements in tensile strength and Young's modulus compared with PDLA material. On the other hand, s-PLA slightly reduces elongation at break compared to PDLA. When compared to previous research, the addition of a small number of s-PLA materials into a PLA homopolymer contributes significant improvements in tensile strength and Young's modulus with a slight reduction in elongation at break.

From the data, the addition of s-PLA and PDLA enhanced mechanical properties in a different pattern. The addition of s-PLA is predicted to enhance mechanical properties through a nucleating effect; however, the addition of PDLA enhanced the mechanical properties through the formation of stereocomplex crystallites and acted as an intermolecular cross-link connecting homopolymer crystallites [21].

We also evaluated the thermal properties that were affected by the addition of sPLA particles and PDLA homopolymers. Based on DSC scanning, the addition of s-PLA enhanced the crystallinity of homopolymers. As shown in Table 2, PLLA homopolymer showed a single melting point $\left(T_{m}\right)$ at $\sim 180{ }^{\circ} \mathrm{C}$, and PLLA blends showed two $T_{m}$ values $\left(T_{m}{ }^{1}=\sim 180{ }^{\circ} \mathrm{C}\right.$ and $\left.T_{m}{ }^{2}=\sim 230{ }^{\circ} \mathrm{C}\right)$. The $T_{m}{ }^{1}$ is the melting point of PLLA homopolymer crystallites and $T_{m}{ }^{2}$ is the melting point of s-PLA crystallites. The heat of melting at high temperature $\left(\Delta H^{2}\right)$ evaluation showed that PDLA has a bigger enthalpy value compared to s-PLA. Theoretically, the same addition of PDLA resulted in approximately double $\Delta H^{2}$ compared with s-PLA due to the PDLA homopolymer percentage being approximately $50 \%$ in s-PLA crystallites. The degree of crystallinity of PLLA/PDLA blends showed a decrease in PLLA crystallites due to some portion of PLLA homopolymers being converted into s-PLA crystallites caused by the hydrogen bonding $\left(\mathrm{CH}_{3} \cdots \mathrm{O}=\mathrm{C}\right.$ interaction) between PLLA and PDLA homopolymers [8]. The s-PLA particle slightly increased the degree of crystallinity of PLLA homopolymer crystallites. The presence of s-PLA particles in the blend was confirmed by the $T_{m}{ }^{2}$ value. The degree of crystallinity $(\chi)$ of s-PLA from the PLLA/PDLA3 blend showed double the value when compared with the PLLA/s-PLA3 
blend. Thus, the thermal evaluation data complies with the theoretical calculation of $T_{m}$ and $\Delta H^{2}$.

Table 2. Thermal properties evaluation by Differential Scanning Calorimeter with scanning speed $10^{\circ} \mathrm{C} / \mathrm{min}$.

\begin{tabular}{cccccccc}
\hline Materials & $\boldsymbol{T}_{\mathbf{m}} \mathbf{1}^{\mathbf{1}}$ & $\boldsymbol{\Delta} \boldsymbol{H}^{\mathbf{1}}$ & $\boldsymbol{T}_{\mathbf{m}}{ }^{\mathbf{2}}$ & $\boldsymbol{\Delta} \boldsymbol{H}^{\mathbf{2}}$ & $\chi^{\mathbf{1}}$ & $\chi^{\mathbf{2}}$ & Xtotal \\
\hline Neat PLLA & 178.10 & 37.83 & - & - & 41.12 & - & 41.12 \\
PLLA/s-PLA3 & 178.02 & 34.17 & 222.30 & 4.693 & 37.14 & 3.30 & 40.44 \\
PLLA/PDLA3 & 179.97 & 37.87 & 227.66 & 2.300 & 41.16 & 1.62 & 42.78 \\
\hline
\end{tabular}

The thermal evaluation data from DSC scanning was confirmed by XRD evaluation as shown in Figure 2. The XRD pattern confirmed the presence of PLLA homopolymer and s-PLA crystallites in the polymer blends. The XRD analysis indicated diffraction peak at $2 \theta=14.6^{\circ}, 17^{\circ}, 19^{\circ}, 23.7^{\circ}$ on homopolymer, whereas diffraction peaks for stereocomplex PLA were observed at $12.5^{\circ}, 21^{\circ}$, and $24^{\circ}$. X-ray diffraction evaluation confirmed the presence of s-PLA crystallites on PLLA/PDLA3 and PLLA/s-PLA3 blends. The area of diffraction peak of PLLA/s-PLA3 was wider than PLLA/PDLA3 blends. This data aligned with DSC evaluation on the degree of crystallinity. The higher crystallinity will affect the flexibility of the material. Higher crystallinity caused materials to be more rigid and brittle which caused decreases in elongation at the break during mechanical testing.

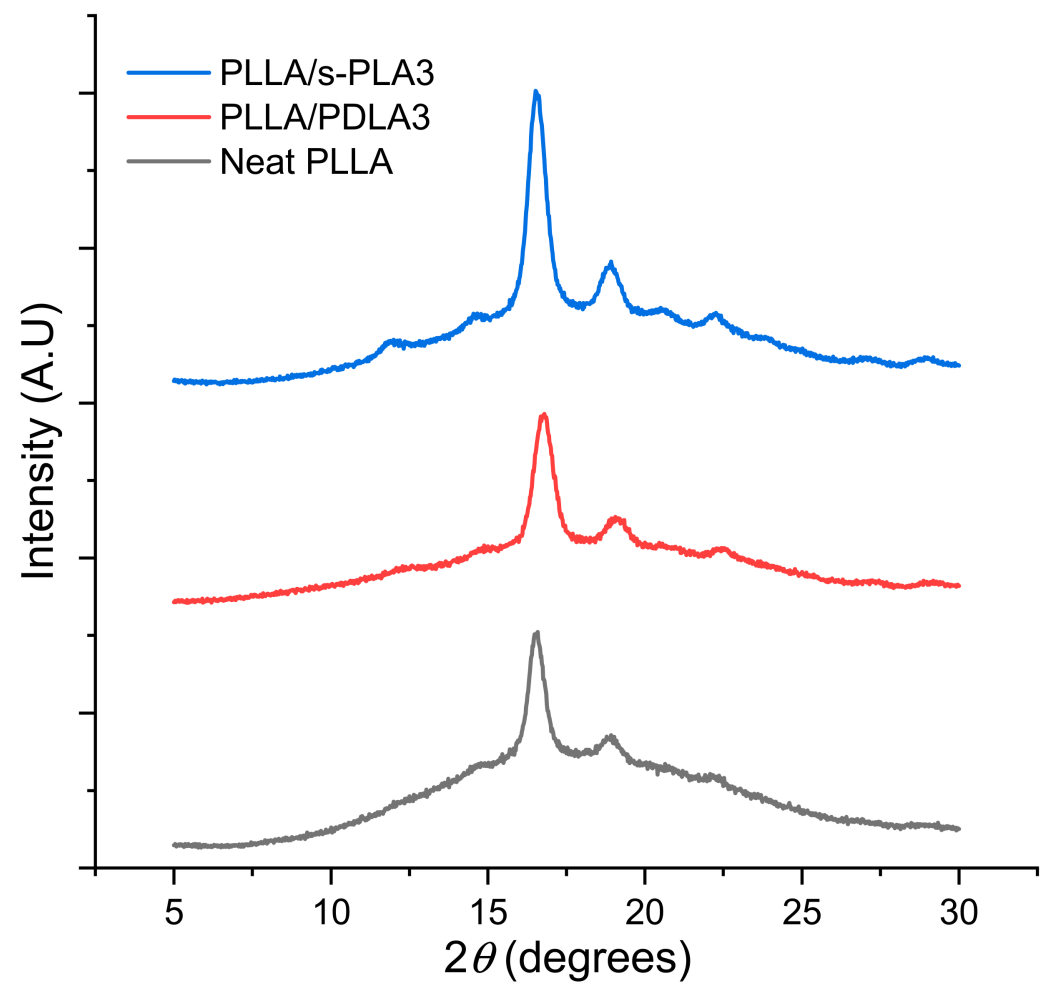

Figure 2. X-ray diffraction pattern of PLLA homopolymer, PLLA/PDLA3 and PLLA/s-PLA blends.

We also evaluated the melt stability characteristics, or the crystallization process after melting of the blends to ensure their suitability in real industrial processes and applications due to the importance of maintaining the physical properties and processability of the materials. The evaluation on melt stability of the blends was performed by a DSC comparing the degree of crystallinity before and after melting at $250^{\circ} \mathrm{C}$ by scanning speed at $10^{\circ} \mathrm{C} / \mathrm{min}$ (shown in Figure 3). The degree of crystallinity of PLLA homopolymer drastically decreases. The degree of crystallinity of PLLA/PDLA blends shows significant improvement in crystallization after melting, but with a high content of PDLA $(10 \%)$, the 
degree of crystallinity drastically decreases in the first and second scanning. Decreases in the degree of crystallinity with high content of PDLA homopolymers are caused by the limitations of high molecular weight PDLA to form stereocomplex crystallites in solution casting (first scan) and to re-assemble the enantiomeric homopolymer chains after melting (second scan) [28]. For the PLLA/s-PLA blends, the degree of crystallinity at the first and second scanning does not have a significant difference compared to PLLA/PDLA blends. From these data, the nucleating effect of s-PLA is more effective compared with PDLA materials due to PDLA materials forming as s-PLA first, then acting as a nucleating agent.

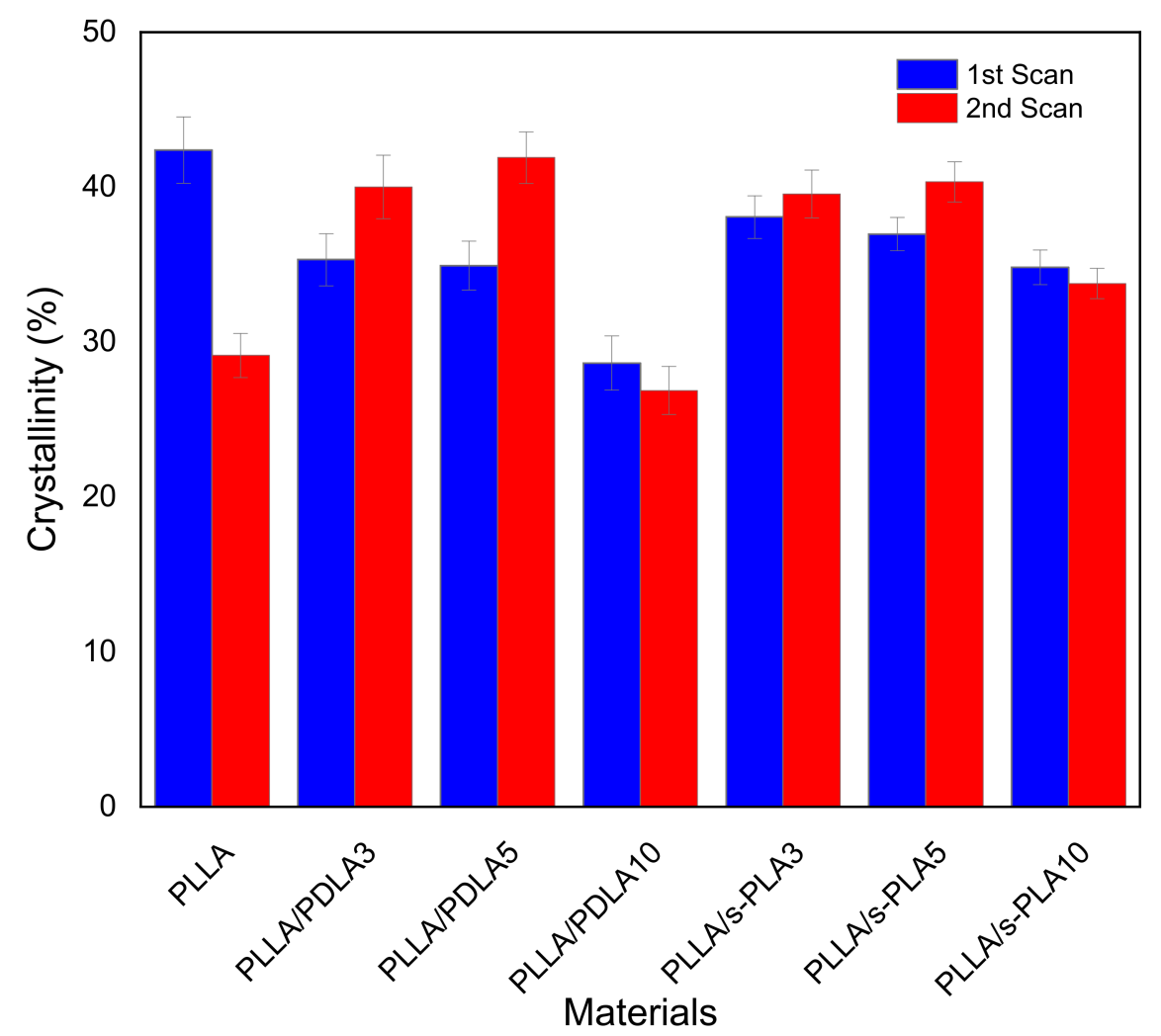

Figure 3. DSC thermogram of first and second scan for PLLA homopolymer, PLLA/PDLA blends, and PLLA/s-PLA blends at scanning rate $10{ }^{\circ} \mathrm{C} / \mathrm{min}$.

Some studies reported the crystallization behavior of PLA homopolymers in the presence of PDLA as a source of s-PLA crystallites [14,27,29]. Here, we also evaluated the non-isothermal and isothermal crystallization behavior of PLLA homopolymers in the presence of PDLA and s-PLA. For non-isothermal crystallization, the materials were heated to $200{ }^{\circ} \mathrm{C}$ at the rate of $10{ }^{\circ} \mathrm{C} / \mathrm{min}$ and held for $3 \mathrm{~min}$ at the same temperature. Based on the non-isothermal crystallization process at different cooling and scanning rates, increasing the scanning rate will decrease the cold crystallization temperature and the heat of melting values as shown in Figure 4. PLLA homopolymers required a certain time to initialize the crystallization process. Aligned with previous reports $[27,29]$, the cold crystallization temperature $\left(T_{\mathrm{c}}\right)$ was increased by a slower cooling rate and the presence of a nucleating agent. The presence of s-PLA crystallites in PLLA homopolymers increased $T_{\mathrm{c}}$ values which correspond to the acceleration of PLLA crystallization [27]. Figure 4 shows the $T_{\mathrm{c}}$ and $\triangle H$ values of PLLA/s-PLA3 at a slow cooling rate are higher when compared with PLLA/PDLA3 which means the nucleating effect of s-PLA will show more significant effects compared with PDLA homopolymers. PDLA homopolymers are probably required to form s-PLA before acting as a nucleating agent. 


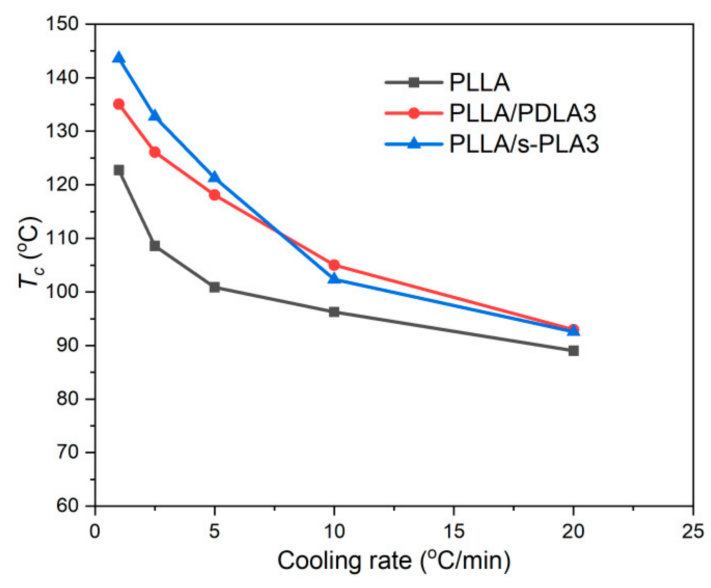

(a)

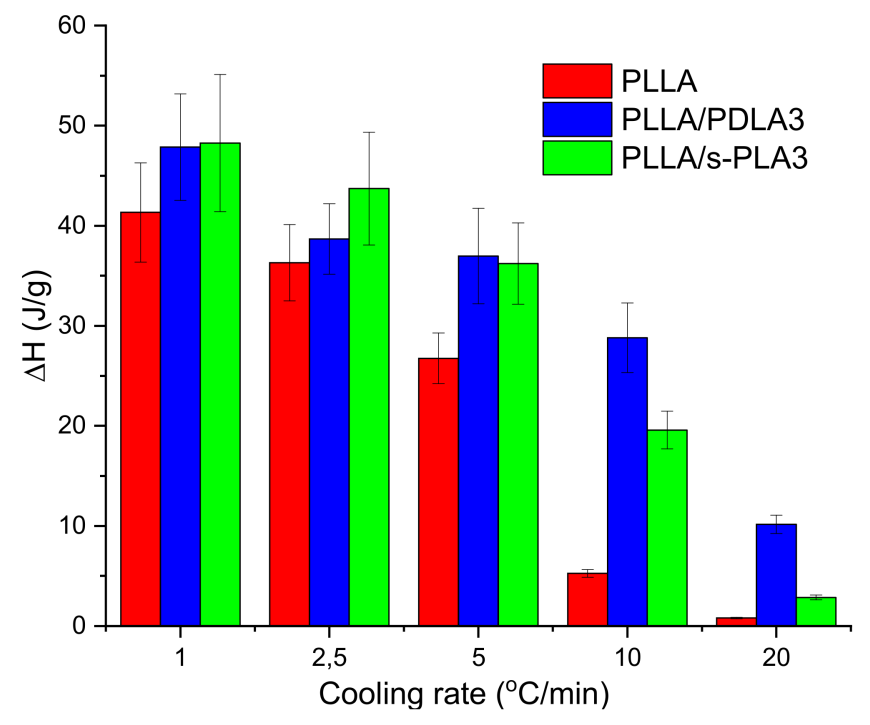

(b)

Figure 4. (a). Change of cold crystallization temperature $\left(T_{\mathrm{c}}\right)$; $(\mathbf{b})$. Heat of melting at different scan rates for PLLA, PLLA/PDL3, and PLLA/s-PLA3.

The crystallization study is important to evaluate the material's behavior during thermal processing. The use of s-PLA as a nucleating agent offers higher effectivity compared with PDLA homopolymer due to PDLA needing to form s-PLA before acting as a nucleating agent. For s-PLA formation during PLLA and PDLA blending, molecular weight and structure is important in structure re-arrangement during the melt. The s-PLA material can act directly as a nucleating agent during the thermal or melt process.

To obtain information about crystallization behavior, the polarized optical microscope was used to evaluate the crystal growth of polymeric materials as shown in Figure 5. Nonisothermal crystallization showed that PLLA materials are able to form crystal structures in the presence or absence of a nucleating agent. The crystal formation shows the different size and number of spherulite per area. PLLA homopolymers show a bigger crystal size compared with PLLA/PDLA3 and PLLA/s-PLA3. It means PLLA homopolymer has a slower initialization of crystal formation. PLLA/s-PLA showed a smaller average crystal size compared with PLLA/PDLA3. Therefore, the s-PLA materials have a faster nucleating effect compared with PDLA materials which should form s-PLA crystallites first before acting as a nucleating agent. At isothermal temperature $120^{\circ} \mathrm{C}, \mathrm{PLLA} / \mathrm{s}-\mathrm{PLA} 3$ and PLLA/PDLA3 showed a higher density of crystallites compared with PLLA homopolymer. The PLLA/s-PLA3 showed smaller crystallite size and higher density compared with PLLA/PDLA3. Based on these data, s-PLA showed a better nucleating agent compared with PDLA homopolymers. 


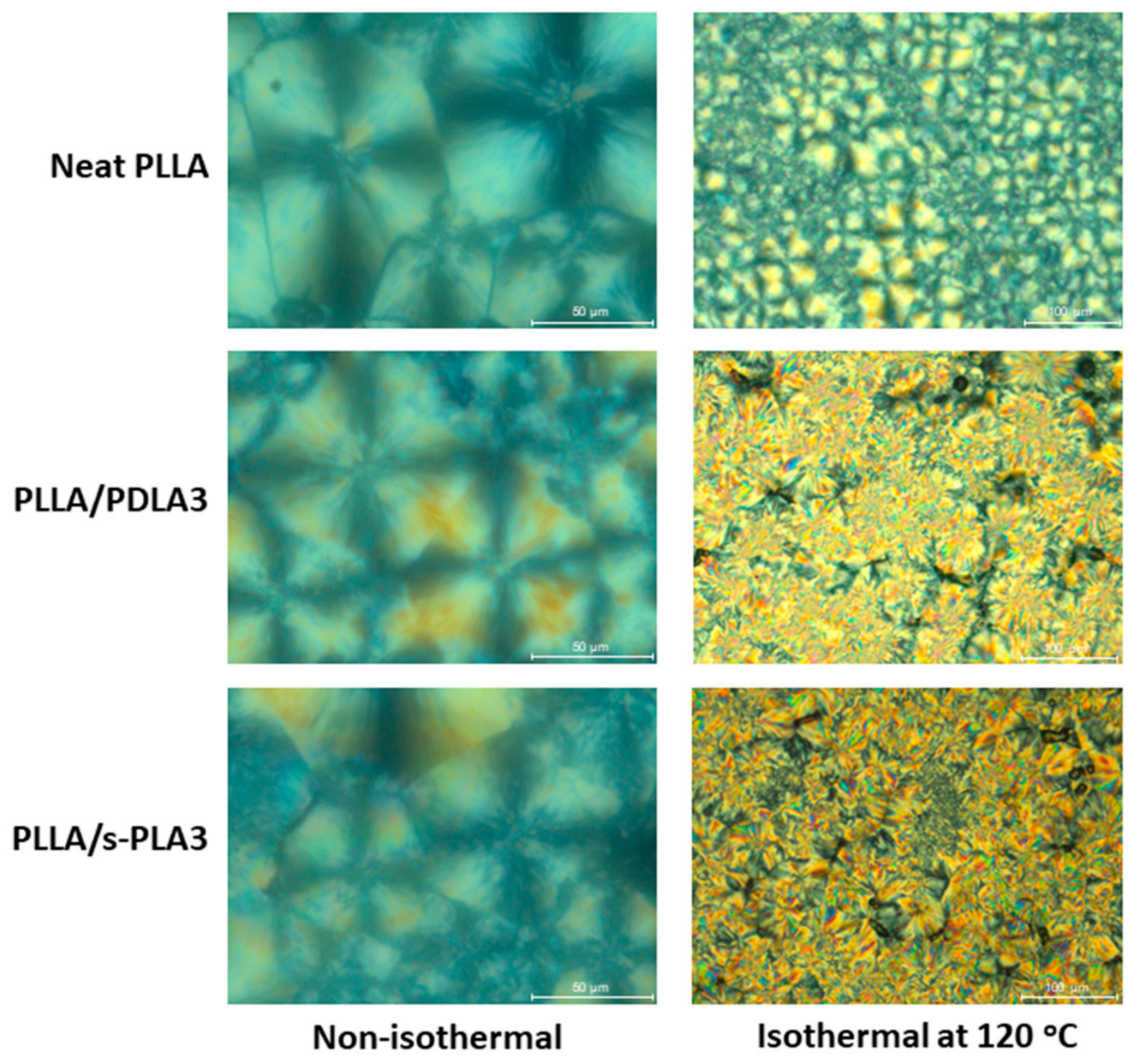

Figure 5. Polarized optical micrographs of PLLA, PLLA/PDLA3, and PLLA/s-PLA3 crystallized through non-isothermal and isothermal crystallization at $120^{\circ} \mathrm{C}$.

\section{Conclusions}

The PDLA and s-PLA materials can be used to increase the thermal and mechanical properties of PLLA homopolymers. S-PLA materials enhanced mechanical properties by increasing the crystallinity of the PLLA homopolymers. PLLA/s-PLA enhanced mechanical properties up to a certain level (5\% s-PLA content), which then decreased due to a higher amount of s-PLA materials affecting the brittleness of the blends. The addition of s-PLA improved mechanical properties by more than $25 \%$ of tensile strength and Young's modulus. PDLA homopolymers increased mechanical properties by forming stereocomplex PLA with PLLA homopolymers. The addition of $10 \%$ PDLA homopolymer improved PLLA homopolymer by up to $11 \%$ of tensile strength and $17 \%$ of Young's modulus. Higher content of PDLA homopolymer has difficulties forming perfect stereocomplexation of PLA due to its limitations caused by molecular weight. Non-isothermal and isothermal evaluation showed that s-PLA materials are more effective in enhancing PLLA homopolymer properties through nucleating agent mechanism.

Author Contributions: Conceptualization, P.P. and M.S.; methodology, P.P., M.S. and I.I.; writing and original draft preparation, P.P. and M.S.; writing, review and editing, P.P., M.S. and I.I. All authors have read and agreed to the published version of the manuscript.

Funding: This research was funded by Kementerian Riset dan Teknologi/Badan Riset dan Inovasi Nasional Republik Indonesia, World Class Research Grant.

Institutional Review Board Statement: Not applicable.

Informed Consent Statement: Not applicable. 
Data Availability Statement: Data is contained within the article.

Conflicts of Interest: The authors declare no conflict of interest.

\section{References}

1. Lunt, J. Large-scale production, properties and commercial application of polylactic acid polymers. Polym. Degrad. Stab. 1998, 59, 145-152. [CrossRef]

2. Vink, E.T.H.; Rabago, K.R.; Glassner, D.A.; Gruber, P.R. Applications of life cycle assessment to NatureWorks ${ }^{\text {TM }}$ polylactide (PLA) production. Polym. Degrad. Stab. 2003, 80, 403-419. [CrossRef]

3. Garlotta, D. A literature review of poly (lactic acid). Polym. Environ. 2001, 9, 63-84. [CrossRef]

4. Ikada, Y.; Tsuji, H. Biodegradable polyesters for medical and ecological applications. Macromol. Rapid Commun. 2000, 21, 117-132. [CrossRef]

5. Gao, C.; Yu, L.; Liu, H.; Chen, L. Development of self-reinforced polymer composite. Prog. Polym. Sci. 2012, 37, 767-780. [CrossRef]

6. Gupta, B.; Revagade, N.; Hilborn, J. Poly (lactic acid) fiber: An overview. Prog. Polym. Sci. 2007, 32, 455-482. [CrossRef]

7. Raquez, J.M.; Habibi, Y.; Murariu, M.; Dubois, P. Polylactide (PLA)-based nanocomposites. Prog. Polym. Sci. 2013, 38, 1504-1542. [CrossRef]

8. Tsuji, H. Poly (lactide) stereocomplexes: Formation, Structure, Properties, Degradation, and Applications. Macromol. Biosci. 2005, 5, 569-597. [CrossRef]

9. Okihara, T.; Tsuji, M.; Kawaguchi, A.; Katayama, K.-I.; Tsuji, H.; Hyon, S.-H.; Ikada, Y. Crystal structure of stereocomplex of poly (L-lactide) andpoly (D-lactide). J. Macromol. Sci. 2006, 30, 119-140. [CrossRef]

10. Wan, Z.Q.; Longo, J.M.; Liang, L.X.; Chen, H.Y.; Hou, G.J.; Yang, S.; Zhang, W.-P.; Coates, G.W.; Lu, X.-B. Comprehensive understanding of polyester stereocomplexation. J. Am. Chem. Soc. 2019, 141, 14780-14787. [CrossRef]

11. Ikada, Y.; Jamshidi, K.; Tsuji, H.; Hyon, S.H. Stereocomplex formation between enantiomeric poly (lactides). Macromolecules 1987, 20, 904-906. [CrossRef]

12. Rahman, N.; Kawai, T.; Matsuba, G.; Nishida, K.; Kanaya, T.; Watanabe, H.; Okamoto, H.; Kato, M.; Usuki, A.; Matsuda, M.; et al. Effect of Polylactide Stereocomplex on the Crystallization Behavior of Poly(L-lactic acid). Macromolecules 2009, 42, 4739-4745. [CrossRef]

13. López-Rodríguez, N.; Martínez de Arenaza, I.; Meaurio, E.; Sarasua, J.R. Efficient stereocomplex crystallization in enantiomeric blends of high molecular weight polylactides. RSC Adv. 2015, 5, 34525-34534. [CrossRef]

14. Ji, N.; Hu, G.; Li, J.; Ren, J. Influence of poly(lactide) stereocomplexes as nucleating agents on the crystallization behavior of poly(lactide)s. RSC Adv. 2019, 9, 6221. [CrossRef]

15. Cheng, L.; Hu, C.; Li, J.; Huang, S.; Jiang, S. Stereocomplex-affected crystallization behavior of PDLA in PDLA/PLDLA blends. Cryst. Eng. Comm. 2019, 21, 329. [CrossRef]

16. Tan, B.H.; Muiruri, J.K.; Li, Z.; He, C. Recent Progress in Using Stereocomplexation for Enhancement of Thermal and Mechanical Property of Polylactide. ACS Sustain. Chem. Eng. 2016, 4, 5370-5391. [CrossRef]

17. Luo, F.; Fortenberry, A.; Ren, J.; Qiang, Z. Recent Progress in Enhancing Poly (Lactic Acid) Stereocomplex Formation for Material Property Improvement. Front. Chem. 2020, 8, 688. [CrossRef]

18. Andersson, S.R.; Hakkarainen, M.; Inkinen, S.; Sodergard, A.; Albertsson, A.-C. Polylactide Stereocomplexation Leads to Higher Hydrolytic Stability but More Acidic Hydrolysis Product Pattern. Biomacromolecules 2010, 11, 1067-1073. [CrossRef] [PubMed]

19. Fujita, M.; Sawayanagi, T.; Abe, H.; Tanaka, T.; Iwata, T.; Ito, K.; Fujisawa, T.; Maeda, M. Stereocomplex Formation through Reorganization of Poly(l-lactic acid) and Poly(d-lactic acid) Crystals. Macromolecules 2008, 41, 2852-2858. [CrossRef]

20. Fukushima, K.; Kimura, Y. Stereocomplexed polylactides (Neo-PLA) as high performance bio-based polymers: Their formation, properties, and application. Polym. Int. 2006, 55, 626-642. [CrossRef]

21. Tsuji, H.; Ikada, Y. Stereocomplex formation between enantiomeric poly (lactic acid)s. XI. Mechanical properties and morphology of solution-cast films. Polymer 1999, 40, 6699-6708. [CrossRef]

22. Karst, D.; Yang, Y. Molecular modeling study of the resistance of PLA to hydrolysis based on the blending of PLLA and PDLA. Polymer 2006, 47, 4845-4850. [CrossRef]

23. Lin, T.; Liu, X.-Y.; He, C. Ab Initio Elasticity of Poly(lactic acid) Crystals. J. Phys. Chem. B 2010, 114, 3133-3139. [CrossRef] [PubMed]

24. Purnama, P.; Kim, S.H. Stereocomplex Formation of High Molecular Weight Polylactide Using Supercritical Fluid. Macromolecules 2010, 43, 1137-1142. [CrossRef]

25. Purnama, P.; Kim, S.H. Rapid Stereocomplex Formation of Polylactide Using Supercritical Fluid Technology. Polym. Int. 2012, 61, 939-942. [CrossRef]

26. Purnama, P.; Jung, Y.; Kim, S.H. Stereocomplexation of Poly(L-lactide) and random copolymer Poly(D-lactide-co- $\varepsilon$-caprolactone) to Enhance Melt Stability. Macromolecules 2012, 45, 4012-4014. [CrossRef]

27. Tsuji, H.; Takai, H.; Saha, S.K. Isothermal and non-isothermal crystallization behavior of poly(L-lactic acid): Effect of stereocomplex as nucleating agent. Polymer 2006, 47, 3826-3837. [CrossRef]

28. Tsuji, H.; Ikada, Y. Stereocomplex formation between enantiomeric poly (lactic acid). 9. Stereocomplexation from the melt. Macromolecules 1993, 26, 6918-6926. [CrossRef] 
29. Li, C.; Dou, Q.; Bai, Z.; Lu, Q. Non-isothermal crystallization behaviour and spherultic morphology of poly(lactic acid) nucleated by a novel nucleating agent. J. Therm. Anal. Calorim. 2015, 122, 407-417. [CrossRef]

30. Purnama, P.; Kim, S.H. Stereocomplex Formation of Polylactide by Microwave Irradiation. Polym. Int. 2014, 63, 741-745. [CrossRef]

31. Sarasua, J.R.; Arraiza, A.L.; Balerdi, P.; Maiza, I. Crystallinity and mechanical properties of optically pure polylactides and their blends. Polym. Eng. Sci. 2005, 45, 745-753. [CrossRef] 